Revista internacional de fronteras, territorios y regiones / International Journal of Borders, Territories and Regions

FRONTERA NORTE VOL. 32, ART. 11, 2020

http://dx.doi.org/10.33679/rfn.v1i1.1964

\title{
Integración de los inmigrantes haitianos de la oleada a México del 2016
}

\section{Integration of Haitian Immigrants of the 2016 Wave in Mexico}

\author{
Schwarz Coulange Méroné ${ }^{1}$ y Manuel Ángel Castillo ${ }^{2}$
}

\section{RESUMEN}

Este artículo analiza el incipiente proceso de integración de los inmigrantes haitianos de la oleada del 2016, que llegaron a México y se asentaron en Tijuana y Mexicali, en Baja California, y en la Ciudad de México. Nos interesa la integración en dos espacios sociales claves: el mercado de trabajo y el campo de las relaciones socioafectivas. Mediante una metodología cualitativa, se evidenció la existencia de diferencias notables en la inserción laboral de los migrantes en las tres ciudades mencionadas, con una clara "ventaja" para los que viven en Tijuana y en Mexicali. Por otro lado, pese al carácter reciente del colectivo haitiano y sus diferencias socioculturales con la comunidad nacional, existen uniones y familias mixtas. Aunque queda un largo camino por recorrer, no cabe duda de que está en marcha un proceso de integración de los haitianos en el país, proceso que se ha apoyado ampliamente en las organizaciones de la sociedad civil, y en el ingenio de esos migrantes.

Palabras clave: 1. inmigrantes haitianos, 2. integración laboral, 3. relaciones socioafectivas, 4. frontera norte 5. México.

\section{ABSTRACT}

This article analyzes the nascent process of incorporation of Haitian immigrants of the 2016 wave in Mexico, especially in Tijuana, Mexicali, and Mexico City. We are interested in integration into two key social spaces: the labor market and socio-affective relationships. Through a qualitative methodology, we document the existence of notable differences in labor insertion in the three cities, with a clear "advantage" for those who live in Tijuana and Mexicali. On the other hand, despite the recent settlement of Haitians and their socio-cultural differences with the Mexican society, there are already mixed marriages and families. Although there is still a lot to achieve, there is no doubt that an integration process is underway, but mostly supported by civil society organizations and the ingenuity of Haitian migrants.

Keywords: 1. Haitian migrants, 2. labor integration, 3. socio-affective relationships, 4. northern border, 5. Mexico.

Fecha de recepción: 26 de febrero del 2019

Fecha de aceptación: 30 de septiembre del 2019

Publicación en web: 10 de agosto de 2020

${ }^{1}$ El Colegio de México, México, schwarzcoulange@gmail.com, https://orcid.org/00000002-8222-2576

${ }^{2}$ El Colegio de México, México, castillo@colmex.mx, https://orcid.org/0000-0002-94139729 
2 Integration of Haitian immigrants of the 2016 wave in Mexico

Coulange Méroné, S. y Castillo, M.A.

\section{INTRODUCCIÓN}

En el año 2016, el territorio mexicano fue escenario del tránsito y estancamiento de un grupo de nacionales de Haití provenientes de una migración previa en países de Sudamérica, lo que ocasionó el desbordamiento de albergues en las ciudades de Tijuana y Mexicali y, en menor grado, en albergues de la Ciudad de México y Tapachula, Chiapas. Así como otros migrantes en tránsito por el país, los haitianos aspiraban cruzar la frontera norte de México e internarse a Estados Unidos, pero el endurecimiento de la política migratoria de ese país y el triunfo de Donald Trump en las elecciones presidenciales de finales del 2016, obligaron a la mayoría a establecerse en México. En otro trabajo exploramos el asentamiento de los haitianos en México, y advertimos que existen indicios de que en ese momento este país se estaba convirtiendo en el nuevo destino de la mayoría (Méroné y Castillo, 2018).

En México, la mayor parte de la población inmigrante está compuesta por personas nacidas en Estados Unidos, pero de padres mexicanos, o por personas procedentes del resto de América Latina; es decir, personas con lazos familiares, culturales e históricos sólidos con el primer país (Conapo, Fundación BBVA Bancomer y BBVA Research, 2018). La situación es otra para los haitianos, cuyo contexto idiosincrásico de origen es distinto y que, antes de la oleada del 2016, contaban con limitadas redes de compatriotas en México. En este sentido, los inmigrantes haitianos plantean un mayor reto en cuanto a su incorporación a la sociedad mexicana, y ofrecen una oportunidad poco usual para analizar la integración de personas con trasfondos culturales disímiles con respecto a los que prevalecen actualmente en México.

En este artículo se analiza la integración de los inmigrantes haitianos en dos ámbitos: el mercado de trabajo y el campo de las relaciones socioafectivas. Nos interesan estas áreas por su conocida trascendencia en una integración más amplia de las poblaciones de origen migrante en sus sociedades de acogida. En efecto, para los inmigrantes la entrada al mercado de trabajo abre el camino para la instauración de los nexos necesarios para su participación más activa en la vida social.

Más allá de ser una fuente regular de ingresos, "el trabajo confiere un estatus social, construye espacios de influencia, marca los ritmos de vida, define las relaciones interpersonales, [y] ofrece la posibilidad de integrarse en la vida social" (Muñoz, 2009, p. 88). Por otro lado, en este trabajo sostenemos la idea de que el establecimiento de lazos socioafectivos entre migrantes y miembros de la sociedad receptora expresa cierta voluntad de los primeros de formar parte de su nuevo contexto social, así como la apertura de los segundos al otro, y su disposición para extender las fronteras del nosotros.

El análisis se basa principalmente en un corpus de información recabada durante un trabajo de campo llevado a cabo entre septiembre y diciembre del 2017 en las ciudades de Tijuana, Mexicali y en la Ciudad de México. Además de notas de campo, se realizaron 56 entrevistas semiestructuradas a haitianos procedentes de Sudamérica, y a un grupo de mexicanos que interactuaron con ellos. Otra fuente de información fueron los registros 
administrativos del Instituto Nacional de Migración, que permitieron establecer un bosquejo del perfil de la población haitiana que llegó a México en 2016.

El artículo está dividido en cuatro secciones. En la primera se revisan algunas aproximaciones teóricas que tratan la integración laboral y las relaciones socioafectivas interétnicas; en la segunda se presentan algunos elementos contextuales de la oleada de haitianos que llegó a México en el 2016. La tercera sección analiza el perfil sociodemográfico de los inmigrantes, y en la última se analiza la integración de esa población en los ámbitos mencionados arriba.

\section{APROXIMACIONES TEÓRICAS SOBRE LA INTEGRACIÓN LABORAL Y LAS RELACIONES MIXTAS}

Los principales enfoques teóricos en torno a la integración laboral de inmigrantes $-\mathrm{y}$ de la población, en términos generales- resaltan, por una parte, el papel de su nivel de dotación en capital humano, y por la otra, su capital social (Becker, 1964; Bourdieu, 2000). La teoría del capital humano sostiene que el acervo de conocimientos, habilidades o experiencias laborales que poseen los individuos determina su inserción, así como su éxito o fracaso en el mercado de trabajo (DeTienne y Chandler, 2007).

Para los inmigrantes, aspectos como el dominio del idioma del país receptor y la duración de la estancia, también son considerados como partes del capital humano (Cornelius, Tsuda y Valdez, 2003; Portes y Rumbaut, 2001; De la Rica y Ugidos, 1995). Entendida de esta manera, la inserción y posteriormente, la integración de los inmigrantes en el mercado de trabajo, así como las diferencias que se expresan en este espacio entre los grupos étnicos, hombres y mujeres, migrantes y no-migrantes, entre otras categorías sociales, se explicarían fundamentalmente por las diferencias de dotación de capital humano.

Sin embargo, desde el credencialismo (Collins, 1979), la teoría de la correspondencia (Bowles y Gintis, 1976), las teorías de la discriminación (Boumahdi, Lattes y Plassard, 2002; Anker, 1997), la perspectiva de género (García y De Oliveira, 1994), o el enfoque espacial (Peláez, González y Pinto da Cunha, 2008; Massey y Denton, 1987), se señala que más allá del capital humano, factores como la raza, el grupo étnico, el género, las dinámicas familiares, el patrón residencial, entre otros, pueden impulsar o dificultar la integración laboral.

Entre poblaciones de origen migrante, esos factores pueden extenderse al origen nacional, la generación -siendo los inmigrantes la primera generación, sus hijos nacidos en el país de llegada la segunda, sus nietos y personas que se adscriben al grupo la tercera generación-, el estatus migratorio de sí mismo o de los progenitores, la posesión o no de herencia nativa, y demás (Méroné, 2019; Bean, Leach, Brown, Bachmeier y Hipp, 2011). Asimismo, es común que la imperfección o imposibilidad de trasladar ciertos componentes del capital humano adquirido en países distintos al de recepción ocasione una discrepancia entre la dotación de 
ese factor y la situación ocupacional de los migrantes (Chiswick, Lee y Miller, 2005; Frijters, Shields y Wheatley Price, 2005). Así, personas con niveles de capital humano similares, pero con características sociales diferentes, pueden encontrarse en condiciones muy dispares en el mercado de trabajo.

Precisamente, en contraste con el capital humano, el enfoque del capital social resalta la relevancia de mecanismos sociales en la adquisición de diferentes tipos de recursos, como pueden ser la inserción y la movilidad en el mercado de trabajo, entre otros (Portes, 1998). Bourdieu (2000) sostiene que el capital social agrupa al conjunto de recursos potenciales y actuales asociados a la pertenencia a una red duradera de relaciones. Así, independientemente del nivel de capital humano del que se disponga, la pertenencia a estructuras socialmente favorecidas o desfavorecidas puede influir en la integración laboral (Marrero, 2006; Vaillant, Fernández y Kaztman, 2001). En concordancia con esta perspectiva, se ha evidenciado que las redes de familiares, de amistad y de connacionales, o la existencia de una economía étnica, permiten una inserción laboral relativamente rápida de los inmigrantes (Elliott y Sims, 2001), aunque esas estructuras pueden terminar por encerrarlos en sectores segregados con pocas perspectivas de movilidad ocupacional (Kalter y Kogan, 2014).

Por otro lado, las relaciones socioafectivas, en especial las uniones maritales mixtas, han sido consideradas como un indicador clave en las aproximaciones teóricas sobre la integración de inmigrantes en sus sociedades de recepción. Por ejemplo, la teoría de la asimilación considera que las uniones interétnicas representan la última etapa de la asimilación de los migrantes, en tanto merman las barreras que dificultan la aceptación social (Gordon, 1964). Las uniones mixtas serían un indicador de que por lo menos los protagonistas directos se aceptan como sujetos sociales iguales, no obstante las desigualdades de género (Telles y Esteve, 2019; Qian y Lichter, 2007).

En el mismo orden de ideas, Kalmijn (1998) explica que el matrimonio mixto puede disminuir las diferencias culturales de las generaciones futuras, ya que es menos probable que los hijos de uniones mixtas se identifiquen con un solo grupo. Además, según el mismo autor, al unirse fuera de su grupo étnico, los individuos pueden abandonar las actitudes negativas que probablemente tienen hacia otros grupos. Asimismo, el matrimonio mixto acercaría tanto a los cónyuges como a sus respectivos grupos étnicos, ya que a menudo, a raíz de su unión, sus redes sociales se acercan y se conectan. Y aunque la interacción aumenta la posibilidad de conflictos interétnicos, también brinda a las personas la oportunidad de conocer la variedad individual entre los miembros del otro grupo, lo cual puede minar, e incluso erradicar sus prejuicios y estereotipos.

\section{Contexto de llegada de la oleada de haitianos a México en el 2016}

Si bien el éxodo de los haitianos puede explicarse en gran parte debido a las desfavorables condiciones estructurales y coyunturales que han afligido a su país (Lundahl, 2011), para comprender la oleada que llegó a México en el año 2016 también deben tomarse en cuenta 
las políticas migratorias de algunos países del continente. En efecto, a raíz del terremoto de enero del 2010 en Haití, varios países sudamericanos comenzaron a implementar políticas de "puertas abiertas" hacia los ciudadanos haitianos, otorgándoles facilidades de entrada, regularizando a los que se encontraban en situaciones irregulares en su territorio, o facilitando la reunificación familiar, entre otras medidas (Duffard Evangelista, 2016). Un número significativo de haitianos aprovechó estas disposiciones conciliatorias para emigrar a diferentes países de esa región. ${ }^{3}$

Brasil fungió como el principal polo de atracción de esa migración debido a la percepción de oportunidades laborales asociadas a las noticias alentadoras que se escuchaban sobre la economía brasileña durante la época, y la organización de la Copa Mundial de Fútbol del 2014 y las Olimpiadas del 2016 en ese país (Fernandes y Gomes de Castro, 2014). Además, ya antes del terremoto del 2010, Brasil gozaba de una opinión favorable en Haití debido a su reputación en el fútbol, y la proporción considerable de afrodescendientes de su población, lo que daba a muchos haitianos la ilusión de ausencia de racismo en este país. Por otro lado, desde el 2004 Brasil se había hecho de un lugar en el cotidiano de los haitianos a través de una fuerte participación en la desaparecida Misión de las Naciones Unidas para la Estabilización de Haití (Minustah), de la que también tenía el mando militar, así como la implementación de una serie de programas de cooperación, la presencia de empresas constructoras, organizaciones civiles e instituciones culturales (Milani, Lazo Vergara, Alba Vega y Charles, 2016). Esas entidades contribuyeron a proyectar una imagen atractiva del país sudamericano en Haití.

Así, muchos haitianos consideraban a Brasil como un país accesible, y como una alternativa a los destinos tradicionales - como Estados Unidos, Canadá o Francia-, cuyas políticas migratorias y de inserción laboral son conocidas por su carácter más restrictivo. Sin embargo, al terminar los eventos deportivos y con el estallido de la crisis económica y política en Brasil en 2014, los haitianos asentados en este país se encontraron con un contexto sociolaboral marcado por la desaparición de miles de puestos de empleo y por turbulencias sociopolíticas recurrentes. Frente a esta situación, empezaron a buscar nuevas alternativas migratorias en la región -redirigiéndose principalmente a Chile- y fuera de ella.

Por otro lado, al igual que los países sudamericanos, después del terremoto del 2010 y debido a otras situaciones de desastre en Haití, el gobierno de Estados Unidos flexibilizó su política migratoria hacia los haitianos, otorgando el Temporary Protected Status a los que se encontraban en territorio estadounidense en situación de residencia irregular o indocumentada. También, el gobierno estadounidense decidió no deportar a aquellos que hubiesen ingresado a aquel país sin la documentación requerida, con excepción de aquellos que fueran considerados como una amenaza para la seguridad nacional (París Pombo, 2018).

${ }^{3}$ Da Silva (2013) y Fernandes y Gomes de Castro (2014) estimaron que para el 2013 más de 20000 haitianos ingresaron solo a Brasil. Según los mismos autores, esta cifra se incrementó a 50000 en 2014. 
Así, ante la desilusión de Brasil como destino permanente, una parte de los haitianos buscaron redirigirse hacia Estados Unidos; otros, que se encontraban en países como Chile, Perú, Ecuador o Venezuela, también se unieron a esa "caravana" con rumbo al norte.

La ruta empieza en Brasil o en Chile, atraviesa consecutivamente Perú, Ecuador, Colombia, Panamá, Costa Rica, Nicaragua, Honduras, Guatemala, México, y termina en Estados Unidos, o en algunos casos, en Canadá (París Pombo, 2018). Muy pocos viajaron en avión y, cuando lo hacían, era principalmente al interior de Brasil, para acercarse a la frontera con Perú. Debido a políticas restrictivas con respecto al tránsito irregular de algunos países de la región, los migrantes tuvieron que hacer la mayor parte del recorrido por vía terrestre, combinando diferentes medios de transporte -autobuses, taxis, motocicletas, lanchas, incluso avanzando a pie en algunos tramos, con la ayuda de polleros-, y buscando pasar inadvertidos en algunos países. Ello los expuso a altos riesgos para su integridad física y moral. No obstante, muchos alcanzaron su meta e ingresaron a Estados Unidos por la frontera norte de México, especialmente por las ciudades de Tijuana y Mexicali (Yee Quintero, 2017).

Sin embargo, Estados Unidos cambió su política migratoria hacia los haitianos en septiembre del 2016; empezó a deportar hacia Haití a aquellos que habían ingresado de manera irregular a su territorio, exceptuando los casos de mujeres embarazadas y personas que acompañaban a menores de edad (París Pombo, 2018). Las deportaciones se reanudaron bajo el argumento de que la situación había mejorado en Haití. Lo anterior provocó el alargamiento de la estancia de los haitianos en territorio mexicano, ya que aquellos que llegaron a México después de esa fecha evitaron intentar ingresar al territorio estadounidense.

Como era de esperarse, esas nuevas circunstancias provocaron el estancamiento de un número considerable de haitianos en estas ciudades (Montoya-Ortiz y Sandoval-Forero, 2018). Organizaciones de la sociedad civil estimaron en más de 4000 el número de haitianos varados en México durante la contingencia migratoria (Yee Quintero, 2017). La mayoría fueron atendidos y hospedados por instituciones civiles, o simplemente por personas y familias animadas por la voluntad de ayudar, ya que después del largo recorrido para alcanzar la frontera México-Estados Unidos, muchos habían agotado sus recursos financieros y la capacidad de apoyo de sus redes. A partir de ese momento, una parte de los que aún se encontraban en el sur del país optó por dirigirse hacia la Ciudad de México, con el fin de evitar la contingencia que se vivía con sus coterráneos en el norte. Fueron esas circunstancias y esas dinámicas las que dieron lugar al asentamiento actual de poblaciones haitianas en Tijuana y Mexicali, así como de buena parte de los que se encuentran ubicados en la Ciudad de México.

Cabe señalar que los haitianos no fueron los únicos en realizar el recorrido desde Brasil a México, sino que solo formaban el mayor contingente entre cubanos, congoleses, indios, bangladesís o nepaleses que también buscaban internarse en Estados Unidos. En el caso de los cubanos, estos buscaban ingresar a este país vía terrestre para, entre otras razones, anticiparse a la posible finalización de los privilegios que les otorgaba la ley conocida como 
de los "pies secos, pies mojados", implementada tras la normalización de las relaciones entre Cuba y Estados Unidos iniciada en el 2014. Efectivamente, la administración Obama canceló los privilegios de la mencionada ley en enero del 2017, lo cual supone que los cubanos son sujetos a las mismas dificultades que otras nacionalidades para poder ingresar a Estados Unidos (Clot y Martínez Velasco, 2018). Así pues, el recorrido de Sudamérica a México por vía terrestre no fue "una temeridad haitiana" sino, como sucede a menudo en contextos de flujos diversos, parte de una dinámica más amplia de movimientos migratorios que respondían a políticas y circunstancias volátiles.

En todo caso, la oleada del 2016 marcó un parteaguas en la presencia haitiana en México. Antes de esa fecha, los nacionales de Haití en el país se caracterizaron por conformar una comunidad pequeña, compuesta por exiliados de la dictadura de los Duvalier, artistas, estudiantes y profesionales que llegaron acompañados de sus familiares (Vega Cánovas y Alba Vega, 2012); y se caracterizaron por cierto grado de dispersión al interior de la Ciudad de México. Si bien a nivel nacional la población haitiana sigue constituyendo una reducida comunidad, en Tijuana y Mexicali conforman ahora una minoría visible, y una parte del paisaje social y étnico que no puede ignorarse.

\section{Rasgos sociodemográficos de los haitianos de la oleada a México del 2016}

Se utilizaron dos criterios para identificar a los integrantes de la oleada que llegó a México en el 2016. Por una parte, se sabe que el Instituto Nacional de Migración (INM) otorgó la visa o tarjeta de visitante por razones humanitarias a la mayoría de los haitianos que ingresaron al país por la frontera sur durante el año 2016; por otra, sabemos que la mayor parte obtuvo dicho documento en 2017. Entonces solo consideramos como integrantes de esa oleada a aquellos que recibieron la tarjeta en 2017, descartando a quienes tenían otra condición de estancia en el país en ese momento, ya que la mayoría no pertenece a la población de interés. Con esos criterios identificamos a 2552 miembros de dicha oleada en los registros del INM sistematizados por la Unidad de Política Migratoria (UMP) (Segob, 2017), que constituyen la muestra analizada en este apartado.

Cabe señalar que los datos disponibles presentan ciertas limitaciones, por ejemplo, no tienen información sobre aquellas personas que por alguna razón no presentaron solicitudes de regularización ante el INM. También debemos mencionar que solo se tiene información sobre quienes recibieron una respuesta positiva por parte del Instituto. Asimismo, aquellos que no pudieron comprobar su nacionalidad haitiana y que el INM considera como apátridas, tampoco aparecen en la base de datos. Sin embargo, la información disponible es suficiente para presentar un bosquejo de los rasgos sociodemográficos más generales de la población haitiana.

Ahora bien, de acuerdo con la gráfica 1 y el cuadro 1, los haitianos de la oleada a México del 2016 tienen un sesgo pronunciado en términos de su composición por sexo. Ocho de cada 10 miembros de esta población son del sexo masculino. Como se dijo en el apartado anterior, 
para la mayoría, llegar a México implicó cruzar un territorio de hasta 10 países; las condiciones difíciles y los riesgos asociados al viaje podrían haber desmotivado a muchas mujeres a emprenderlo. Además, la migración previa -hacia Brasil y otros destinos sudamericanos- tenía un componente masculino mayor (Baeninger y Peres, 2017). Por otra parte, la mayor flexibilidad de las autoridades migratorias estadounidenses hacia las mujeres embarazadas y hacia aquellas que iban acompañadas de menores, sin duda afectó la composición por sexo de quienes se quedaron en México.

Gráfica 1. Pirámide poblacional de los haitianos de la oleada a México del 2016.

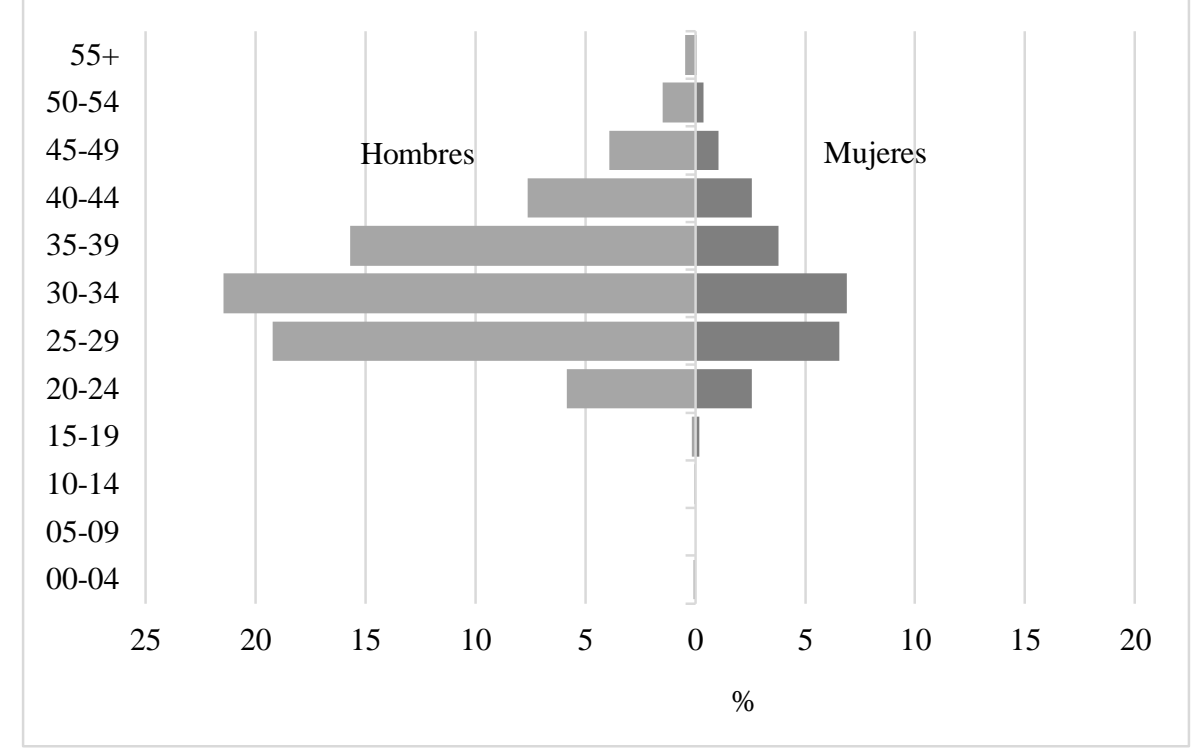

Fuente: Elaboración propia con datos de la UPM (Segob, 2017).

Con respecto a la composición etaria, los datos muestran que los haitianos se concentran en edades económicamente activas, con un promedio de 33 años (cuadro 1). Este dato señala el predominio laboral del flujo y la casi ausencia de menores, lo que puede deberse a las difíciles condiciones del viaje desde Sudamérica y a la mayor tasa de admisión de esa categoría a Estados Unidos. En lo que respecta a los niveles de escolaridad, la mayoría de los haitianos tienen estudios de secundaria o niveles más avanzados, aunque un tercio no especificó su escolaridad. Si estos niveles no permiten acceder a los segmentos laborales con demandas de mano de obra calificada y con las mejores condiciones laborales y salariales, podrían contribuir a evitar que se inserten en los eslabones más bajos del mercado. Además, esos niveles de escolaridad ofrecen mayores posibilidades para quienes deseen ingresar a instituciones de formación técnica o superior, lo cual facilitaría su desempeño laboral futuro.

En el plano familiar, seis de cada 10 haitianos de la oleada del 2016 son solteros (cuadro 1). Aunque no disponemos de información sobre sus posibles compromisos no matrimoniales -noviazgo u otro-, se puede pensar que buena parte está en el mercado matrimonial. Resultaría sugerente analizar en un futuro sus comportamientos en términos de uniones homogámicas o mixtas. En todo caso, en el próximo apartado analizamos los inicios de lazos 
socioafectivos con ciudadanos mexicanos, pero, como veremos, esperamos que estudios futuros profundicen este aspecto. Por otro lado, casi la mitad de los haitianos tiene al menos un hijo ya sea que se encuentren en Haití o en los países de migración previa (cuadro 1), lo cual habla tanto de posibles relaciones de pareja previas como de responsabilidades actuales que pueden estimular la participación laboral.

Cuadro 1. Características seleccionadas de los haitianos de la oleada a México del 2016 según sexo (porcentaje)

\begin{tabular}{lccc}
\hline Características & Hombres & Mujeres & Total \\
\hline Sexo & 75.9 & 24.1 & 100 \\
Edad promedio & 33.3 & 32.4 & 33.1 \\
$\mathrm{~N}$ & 1937 & 615 & 2552 \\
\hline Escolaridad (25+) & & & \\
\hline Ninguno & 0.6 & 0.3 & 0.5 \\
Primaria & 8.0 & 5.6 & 7.4 \\
Secundaria & 36.9 & 41.0 & 37.9 \\
Preparatoria & 14.3 & 14.0 & 14.3 \\
Carrera técnica, comercial o universidad & 7.1 & 4.8 & 6.5 \\
No especificado & 31.1 & 34.3 & 33.4 \\
Total & 100 & 100 & 100 \\
$\mathrm{~N}$ & 1855 & 586 & 2441 \\
\hline Estado civil (15+) & & & \\
\hline Solteros & 63.3 & 58.9 & 62.2 \\
Unidos & 31.4 & 37.1 & 32.8 \\
Otros & 5.3 & 4.0 & 5.0 \\
Total & 100 & 100 & 100 \\
$\mathrm{~N}$ & 1859 & 591 & 2450 \\
\hline Tiene hijos (15 años y más) & \multicolumn{3}{c}{} \\
\hline Sí (al menos uno) & 46.9 & 42.8 & 45.9 \\
No & 20.0 & 22.3 & 20.5 \\
No especificado & 33.1 & 34.9 & 33.6 \\
Total & 100 & 100 & 100 \\
$\mathrm{~N}$ & 1859 & 591 & 2450 \\
\hline
\end{tabular}

Fuente: Cálculos propios con datos del INM sistematizados y publicados en línea por la UPM (Segob, 2017).

\section{TRABAJO DE CAMPO: MÉTODOS Y CARACTERÍSTICAS DE LOS ENTREVISTADOS}

Se utilizó un guion de entrevista para los haitianos y uno distinto para los mexicanos. En ambos casos, el guion era suficientemente flexible para integrar las preguntas y reformulaciones que iban surgiendo, así como para realizar ajustes que respondían a características específicas de las personas entrevistadas. Por último, es preciso señalar que las entrevistas a los haitianos se realizaron originalmente en creole, por lo que los fragmentos en español utilizados en este artículo son traducciones nuestras. 
10 Integration of Haitian immigrants of the 2016 wave in Mexico

Coulange Méroné, S. y Castillo, M.A.

En el cuadro 2 presentamos algunas de las características de los entrevistados. Como se puede apreciar, son mayoritariamente hombres en edades productivas, con estudios de secundaria o niveles más avanzados, y fuera de algún tipo de unión conyugal. Aunque los porcentajes son diferentes, a grandes rasgos estas características se parecen bastante a las analizadas con los datos del INM en el apartado anterior.

Cuadro 2. Características de los entrevistados seleccionados, por ciudad y origen

\begin{tabular}{|c|c|c|c|c|c|c|c|}
\hline \multirow[t]{2}{*}{ Características } & \multicolumn{2}{|l|}{ Tijuana } & \multicolumn{2}{|c|}{ Mexicali } & \multicolumn{2}{|c|}{ Ciudad de México } & \multirow{2}{*}{ Total } \\
\hline & Haitianos & Mexicanos & Haitianos & Mexicanos & Haitianos & Mexicanos & \\
\hline \multicolumn{8}{|c|}{ Sexo (porcentaje) } \\
\hline Hombres & 68.2 & 40.0 & 72.7 & 50.0 & 80.0 & 50.0 & 66.1 \\
\hline Mujeres & 31.8 & 60.0 & 27.3 & 50.0 & 20.0 & 50.0 & 33.9 \\
\hline Total & 100 & 100 & 100 & 100 & 100 & 100 & 100 \\
\hline \multicolumn{8}{|c|}{ Grupo de edad (porcentaje) } \\
\hline $20-34$ & 36.4 & 40.0 & 36.4 & 33.3 & 70.0 & 50.0 & 42.9 \\
\hline $35-49$ & 50.0 & 60.0 & 63.6 & 50.0 & 20.0 & 50.0 & 48.2 \\
\hline 50 y más & 13.6 & 0.0 & 0.0 & 16.7 & 10.0 & 0.0 & 8.9 \\
\hline Total & 100 & 100 & 100 & 100 & 100 & 100 & 100 \\
\hline \multicolumn{8}{|c|}{ Estado civil (porcentaje) } \\
\hline Soltero & 40.9 & 20.0 & 36.4 & 16.7 & 70.0 & 100.0 & 42.9 \\
\hline Unido & 36.4 & 80.0 & 63.6 & 83.3 & 30.0 & 0.0 & 48.2 \\
\hline Otros & 22.7 & 0.0 & 0.0 & 0.0 & 0.0 & 0.0 & 8.9 \\
\hline Total & 100 & 100 & 100 & 100 & 100 & 100 & 100 \\
\hline \multicolumn{8}{|c|}{ Escolaridad (porcentaje) } \\
\hline Ninguno & 9.1 & 0.0 & 0.0 & 0.0 & 0.0 & 0.0 & 3.6 \\
\hline Primaria & 22.7 & 0.0 & 18.2 & 0.0 & 10.0 & 0.0 & 14.3 \\
\hline $\begin{array}{l}\text { Secundaria y } \\
\text { más }\end{array}$ & 68.2 & 100.0 & 81.8 & 100.0 & 90.0 & 100.0 & 82.1 \\
\hline Total & 100 & 100 & 100 & 100 & 100 & 100 & 100 \\
\hline $\mathrm{N}$ & 22 & 5 & 11 & 6 & 10 & 2 & 56 \\
\hline
\end{tabular}

Fuente: Elaboración propia con información recabada en el trabajo de campo realizado de septiembre a diciembre del 2017.

\section{INTEGRACIÓN EN EL MERCADO DE TRABAJO. ENTRE LA DECEPCIÓN Y LA RESIGNACIÓN}

Como se señaló antes, sin ser una panacea, el mercado de trabajo puede constituirse como un motor para la integración de los migrantes en tanto los ponga en relación con otras esferas de la sociedad receptora. En este sentido, el mercado puede funcionar como una plataforma que impulsa las interacciones e intercambios entre los migrantes y su sociedad de acogida. En el siguiente apartado analizamos cualitativamente la inserción laboral de los haitianos de la oleada a México del 2016. 
Ahora bien, los canales a través de los que los haitianos se insertaron en el mercado en los tres sitios estudiados son muy parecidos entre sí, aunque con algunas diferencias entre las dos ciudades del norte y la Ciudad de México. En Tijuana y Mexicali la información recabada sugiere que al principio fueron empleadores de maquilas quienes se acercaban a los albergues para solicitar mano de obra haitiana. También al inicio hubo responsables de albergues que solicitaron a diferentes empresas que contrataran a los haitianos. En un segundo momento, fueron los haitianos los que, al descubrir esa oportunidad, se movilizaron para solicitar trabajo en las fábricas. Posteriormente, la inserción de la mano de obra haitiana en este sector se intensificó por medio de las acciones clásicas de redes de compatriotas o amistades; es decir, cuando quienes laboraban en algún establecimiento llevaban a personas cercanas si en la empresa se requerían de otros trabajadores.

En cuanto a los entrevistados que residen en la Ciudad de México, la mayor parte de aquellos que se alojaron en los albergues se benefició de cierto asesoramiento para conseguir algún tipo de empleo. Así como en las ciudades fronterizas, muchos consiguieron sus primeras ocupaciones remuneradas en la Ciudad de México por medio de sus centros de acogida. Sin embargo, debido a una serie de barreras, esas ocupaciones eran temporales y estaban circunscritas a segmentos laborales socialmente desprotegidos y desvalorizados. No obstante, esas primeras incursiones en el mercado abrieron cauces que les permitieron acceder a cierta autonomía financiera para salir de los albergues y para sobrevivir por sus propios medios.

Por otro lado, las primeras inserciones en el mercado generaron expectativas laborales elevadas con respecto a vivir en México; algunos llegaron a pensar que tendrían aperturas semejantes a las que gozaban en Brasil, especialmente una relativa sencillez para acceder a la residencia permanente y un pronto acceso a ingresos cuantiosos, y beneficios sociales. Para algunos, "México era el hermano menor de Estados Unidos" en cuanto a oportunidades de trabajo. El desencanto empezó a generarse cuando descubrieron que el estatus de visitante por razones humanitarias no les permitía conseguir los beneficios que esperaban. Para acceder al mercado de trabajo formal y obtener las prestaciones legales es necesario tener la Clave Única de Registro de Población (CURP), misma que no es posible obtener con la condición de visitante por razones humanitarias. Esta dificultad redujo sus opciones de trabajo a la industria maquiladora, a ocupaciones informales o a puestos de trabajo en eslabones más bajos de la jerarquía de los empleos, sin importar su nivel de dotación de capital humano.

Un ejemplo de lo anterior es el caso de Jacob -todos los nombres utilizados para referirse a los entrevistados son ficticios-, quien se estableció en la Ciudad de México después de haber relegado a un segundo plano sus pretensiones de ingresar a territorio estadounidense. A pesar del sentimiento de "fracaso" que experimentó al renunciar al sueño americano, se forjó nuevas expectativas en México. 
A Jacob lo entrevistamos por primera vez en septiembre del 2017 en la Ciudad de México, y la segunda en diciembre del mismo año, en Tijuana; la primera vez tenía cuatro meses de haber conseguido empleo en una empresa al norte de la Ciudad de México. Esa empresa lo contrató, pese a que carecía de los documentos legales requeridos a los migrantes para obtener un empleo. En cambio, fue sometido a jornadas de alrededor de diez horas por un salario que califica de miseria. Jacob aceptó ese trabajo después de haber fracasado en repetidas ocasiones en sus intentos por conseguir un empleo en otras empresas. Expresó:

Tengo la tarjeta [de visitante por razones humanitarias] pero no sirve. Cada vez que pedía trabajo en algún lugar, lo primero que me pedían es la CURP, pero no me la quieren dar [...]. Esa empresa no me exigió la CURP, pero no me ofreció trabajo con dignidad, no me valoran. Si hubiera sabido que terminaría así, nunca hubiera salido de Brasil, a pesar de todo (Jacob, 36 años, universidad incompleta, soltero, dos años de experiencia en Brasil, comunicación personal, 20 de septiembre del 2017).

La frustración de Jacob no es un caso aislado; la mayoría de los entrevistados, principalmente los establecidos en la Ciudad de México, expresan una desilusión semejante al percibir que las oportunidades de trabajo están por debajo de sus expectativas. Otro ejemplo es Marie-Line, quien vivió 11 meses en la Ciudad de México antes de trasladarse a Tijuana. Migró a Brasil en 2014 "en busca de una vida mejor para [su] familia". En Caxias do Sul -Brasil- vivió y trabajó en un restaurante hasta octubre del 2016. Después de perder su trabajo y múltiples intentos fallidos para reinsertarse laboralmente, decidió unirse a la oleada haitiana que se dirigía a Estados Unidos. Tras recibir la noticia de la victoria de Donald Trump como presidente de ese país mientras se encontraba en Panamá, optó por continuar hasta México porque "había escuchado que México es un gran país, un país de oportunidades [...] y porque tiene frontera con Estados Unidos”. Sin embargo, después de 10 meses en la Ciudad de México sin lograr ingresar el mercado de trabajo, explica:

México es muy difícil. En todas partes me piden el número de Seguro Social, pero no me lo quieren dar porque la tarjeta es de visitante. [...] No veo el beneficio de venir a México; (Marie-Line, 35 años, preparatoria incompleta, soltera, dos años de experiencia en Brasil, Ciudad de México; comunicación personal, 20 de septiembre del 2017).

Además de la falta de documentos, la mayoría de los haitianos carece de conocimiento sobre el mercado laboral mexicano. Asimismo, al comienzo no contaban con una comunidad consolidada de compatriotas, por lo tanto, de redes sociales propias capaces de orientarlos. Por otro lado, la mayoría no domina el idioma español, lo cual constituye otra desventaja para insertarse laboralmente. En un contexto así, en un principio, se dirigieron hacia las organizaciones especializadas en apoyar a migrantes, mismas que asesoraron a algunos en su inserción al mercado laboral.

Pero, aun con los apoyos institucionales, no está garantizada la inserción laboral en segmentos formales mejor pagados y con prestaciones sociales. El poco dominio del idioma, la falta de redes, el bajo nivel de escolaridad o la dificultad para hacer valer la experiencia 
laboral adquirida en otros mercados siguen imperando como retos a dicha inserción. Un caso típico de esta situación es el de Étienne. Cuando llegó a México en noviembre del 2016 después de salir de Curitiba, Brasil- se imaginaba en la antesala de Estados Unidos; pero, así como a varios de sus connacionales, las autoridades migratorias lo consideraron apátrida, porque no contaba con documentos que acreditaran su nacionalidad haitiana. Debido a este estatus, las autoridades le otorgaron la residencia permanente con permiso para trabajar. Aun así "no fue sencillo" insertarse laboralmente, pues no dominaba el español y carecía de conocidos o de personas en quiénes apoyarse para conseguir empleo. Étienne relata:

Un día, un compañero me dijo que estaban reclutando en su trabajo. Era en [la construcción de] un edificio. Fui con él y me aceptaron. No entendía las instrucciones en el trabajo; me despidieron después de cuatro días (Etienne, 54 años, primaria incompleta, casado, cuatro años de experiencia en Brasil, Ciudad de México; comunicación personal, 20 de octubre del 2017).

Otro ciudadano haitiano que experimentó una situación similar a la de Étienne es Jonas, un mecánico de 28 años. Vivió dos años en São Paulo, donde trabajó principalmente en una empresa que proporcionaba servicios de limpieza en hoteles. Cuando ingresó a México en diciembre del 2016, las autoridades le otorgaron la residencia permanente, ya que fue considerado como apátrida. Al abordar el tema de su inserción laboral, explica:

No he visto el beneficio de la tarjeta [de residencia permanente]. No he podido conseguir trabajo en mi oficio. Me piden el diploma traducido y legalizado. ¿Dónde voy a conseguir el dinero para mandar a sacarlo en Haití? [...] Con tarjeta o sin tarjeta todos estamos en el mismo barco, no hay diferencia (Jonas, 28 años, preparatoria incompleta, soltero, dos años de experiencia en Brasil, Ciudad de México; comunicación personal, 15 de octubre del 2017).

A diferencia de los haitianos que se quedaron en la Ciudad de México, la mayoría de aquellos que se establecieron en Tijuana y Mexicali no experimentaron esas dificultades para insertarse en el mercado de trabajo. Los informantes de esas ciudades expusieron diferencias notables en cuanto a su inserción laboral. Como se mencionó arriba, al principio eran los empleadores quienes se acercaban a los albergues, o directamente con los haitianos, para solicitar su mano de obra.

Constantin se acuerda que "todas las mañanas llegaban [personas] al albergue para ofrecer trabajo [a los haitianos]" (Constantin, 46 años, Tijuana, primaria incompleta, casado, tres años de experiencia en Brasil, comunicación personal, 18 de diciembre del 2017). Kenia, de 42 años de edad, confirma y explica que "había diferentes opciones de trabajo [...] ofrecían trabajo en fábricas, en restaurantes, en casas particulares, en el campo fuera de la ciudad" (Kenia, Tijuana, primaria completa, casada, un año de experiencia en Brasil y un año en Chile; comunicación personal, 11 de diciembre del 2017).

En el mismo orden de ideas, Magofi, experiodista y maestro de idiomas, explica:

La gente [de Mexicali] está acostumbrada a ver a migrantes [...]. Vinieron a ofrecer ayudas, [...] a ofrecer trabajo. Nos sirvió para 
tener algo de dinero, [...] esos trabajos eran como una terapia después de ese camino agotador (Magofi, 35 años, Mexicali, universidad incompleta, soltero, tres años de experiencia en Brasil; comunicación personal, 22 de diciembre del 2017).

Al contrario de lo que ocurrió en la Ciudad de México, tanto en Mexicali como en Tijuana al principio algunos inmigrantes rechazaron las ofertas de trabajo debido a la esperanza de poder cruzar la frontera. Por ejemplo, Thermilus explica que sus amigos y él se rehusaron firmemente a una propuesta para trabajar en una fábrica en Mexicali, arguyendo que "no vinimos a México para trabajar [...]. Era como aceptar una derrota. Todo ese camino, los sufrimientos, los esfuerzos, todo en vano. Yo no quería, convencí a mis amigos para que no fueran [al trabajo]" (Thermilus, 26 años, Mexicali, universidad incompleta, soltero, dos años de experiencia en Brasil, comunicación personal, 27 de diciembre del 2017). Por su parte, Senat explica con remordimiento:

Ahora me río de ver que trabajo dócilmente. Era un revolucionario [...] un oponente a que trabajemos en México. [...] Hasta el último momento pensé que nos iban a dejar cruzar [la frontera]. No podía creer que hubiéramos recorrido todo ese camino y fracasar aquí en la puerta de Estados Unidos (Senat, 54 años, universidad incompleta, Tijuana, separado, cuatro años de experiencia en Guyana Francesa; comunicación personal, 14 de diciembre del 2017).

Así como Senat, la mayoría de las personas que entrevistamos en Tijuana y Mexicali estaba trabajando en el momento de las entrevistas. Buena parte explicó que consiguió trabajo en las maquilas, restaurantes, o empresas privadas. Otros se insertaron en la parte informal de la economía, vendiendo artículos de todo tipo en esquinas o en cruceros estratégicos, e incluso en los puntos de cruce de la frontera con Estados Unidos. También algunos indicaron haber montado micro negocios - a la par con otras ocupaciones o con dedicación exclusivaofreciendo servicios como peluquería, salón de belleza, cibercafé, restaurantes de comida haitiana, o "consultorios" de medicina tradicional haitiana.

En todo caso, la información recabada en campo muestra que el mercado de trabajo presenta mayor apertura en las ciudades fronterizas que en la Ciudad de México. Además, la mayor concentración de la población en Tijuana y Mexicali propicia la eclosión de los negocios destinados a la comunidad y encabezados -aunque no siempre - por miembros del colectivo. Asimismo, favorece la organización de tandas que, en muchas ocasiones, sirven de mecanismos de capitalización de negocios por cuenta propia.

Esta diferencia con la capital del país ocasionó que varios de los que se asentaron ahí al principio se redireccionaran a Tijuana o Mexicali. De hecho, cuatro de nuestros informantes de Tijuana fueron entrevistados en la Ciudad de México en un primer momento, todos confirmaron que pudieron comprobar dicha diferencia en su experiencia en los dos lugares. Por ejemplo, cuando le pedimos su opinión a Marie-Line sobre las diferencias entre la Ciudad de México y Tijuana en términos de oportunidades laborales, contestó: 
Llegué [a Tijuana] y tres días después entraba a trabajar a una fábrica. No piden los papeles que me pedían allá. [...] La mayoría de los haitianos en Tijuana trabajan; aquí, aquel que no trabaja, es porque no quiere (Marie-Line, 35 años, Tijuana, preparatoria incompleta, soltera, dos años de experiencia en Brasil; comunicación personal, 11 de diciembre del 2017).

Este relato de Marie-Line encuentra un eco entre la mayor parte de los haitianos entrevistados en Tijuana y Mexicali; expresan prácticamente la misma opinión sobre la mayor apertura del mercado en estas ciudades, misma que aprovecharon, ya que en el momento de la entrevista, la mayoría trabajaba; lo anterior generaba cierta admiración entre habitantes de esas ciudades.

Los ciudadanos mexicanos que entrevistamos se expresaron en términos elogiosos respecto del desempeño de los haitianos. Expresiones tales como "son muy trabajadores", "son unos luchones", o "nunca los he visto pidiendo limosna" se encuentran dentro de las que usaron para opinar sobre los haitianos. En Mexicali, Alicia explica: "la verdad, al principio no me agradaba la idea de que se vinieran aquí, me generaba conflicto. Pero cuando vi cómo se desempeñan, cómo trabajan duro, no andan pidiendo dinero, cambié totalmente de opinión. Los felicito" (Alicia, mexicana, 32 años, Mexicali, preparatoria completa, taxista, comunicación personal, 28 de diciembre del 2017).

Como se sabe, la inserción en el mercado de trabajo no es sinónimo de satisfacción laboral. Esto se observó entre los haitianos entrevistados tanto en la Ciudad de México como en las ciudades fronterizas. El principal factor de insatisfacción son los niveles de los salarios. La mayoría de los entrevistados considera que los salarios que se pagan en México son "insuficientes para responder a [sus] necesidades", o que reciben "salarios de miseria". En efecto, además de sus obligaciones cotidianas en México, muchos tienen responsabilidades en Haití o en otros países (Brasil, Chile, República Dominicana). Así, lo que ganan en México no alcanza para enviar remesas (en dólares) a los familiares.

Sin embargo, la severidad de los comentarios parecía asociarse con la duración de la experiencia laboral en Sudamérica. Aquellos que habían trabajado dos o más años en algún país del subcontinente tenían relatos tales como: "Brasil era mejor", "prefería el trabajo que tenía, pagaban mejor", o "el real -la divisa brasileña- es más fuerte que el peso [mexicano]". Otros explicaban que "se paga poco, pero si ahorras puedes realizar algunas cosas". Este último discurso se escuchaba más frecuentemente entre aquellos que tenían una experiencia de trabajo corta en países sudamericanos. Para ellos, la referencia es el mercado laboral de Haití, caracterizado por altas tasas de desempleo.

En todo caso, algunos de los mexicanos entrevistados consideraron los discursos severos sobre los salarios en México "desafortunados", "fuera de lugar", e incluso "propios de personas malagradecidas". Sin embargo, otros coinciden en que "en México [...] dependiendo del tipo de trabajo que uno hace, los salarios pueden ser decepcionantes"; (Israel, mexicano, 34 años, Mexicali, universidad, líder de organización de la sociedad civil, 
comunicación personal, 20 de diciembre del 2017), o que "muchos mexicanos ganan muy poco también [...] no es una cuestión de discriminación al extranjero" (José, mexicano, 36 años, Ciudad de México, preparatoria completa, taxista, comunicación personal, 31 de diciembre del 2017).

En cuanto a la percepción sobre el ambiente en los espacios de trabajo, los entrevistados tenían discursos diferenciados según se encontraban en la Ciudad de México o en las ciudades fronterizas. La mayoría de los entrevistados en la capital mexicana manifestaban que los "explotan excesivamente". Además, una parte importante consideraba que recibían un "trato diferente de sus compañeros mexicanos". Por ejemplo, Jacob explica:

Mis compañeros [haitianos] y yo estamos en un puesto muy peligroso. [...] Nos dijeron que nos enviarían a otro menos peligroso cada vez que entre un nuevo empleado. Entran varios mexicanos, los envían directamente a puestos menos peligrosos (Jacob, 36 años, Ciudad de México, universidad incompleta, soltero, dos años de experiencia en Brasil; comunicación personal, 20 de septiembre del 2017).

Así como Jacob, Pierre, que trabajaba como ayudante en un restaurante en el norte de la Ciudad de México, explica: "no sé si es porque somos extranjeros, o porque no tenemos papeles, nos dejan los trabajos más difíciles. Creen que no nos damos cuenta" (Pierre, 26 años, Ciudad de México, preparatoria incompleta, soltero, dos años de experiencia en Brasil; comunicación personal, 20 de octubre del 2017). Por su parte, Inot, que laboraba en otro restaurante, dijo:

[...] pensaba que todos los que trabajamos en la limpieza ganábamos lo mismo. Hace poco supe que a los mexicanos les pagan más. [...] Un compañero [mexicano] me dijo que no es justo, que renunciara y fuera a trabajar a otro lugar. Tiene razón, pero va a ser difícil, [porque] no tengo papeles (Inot, 24 años, Ciudad de México, preparatoria incompleta, soltero, tres años de experiencia en Brasil; comunicación personal, 20 de octubre del 2017).

Por su parte, los haitianos de Tijuana y Mexicali consideraron que las "jornadas [eran] largas", pero la mayoría apreciaba que "el trato [por parte de los jefes] es respetuoso", que "no hay diferencia entre haitianos y mexicanos".

En cuanto a la relación con sus compañeros mexicanos, la mayoría opina que el "ambiente está muy jovial". Marie-Line explica que es "una estrella en el trabajo. Todos quieren hacer equipo conmigo" (Marie-Line, 35 años, Tijuana, preparatoria incompleta, soltera, dos años de experiencia en Brasil; comunicación personal, 11 de diciembre del 2017).

Por su parte, Renaud expresa: "trabajaba en una dulcería, parecía que le caía mal a uno de los compañeros. Una vez se expresó con una palabra racista conmigo. Fuera de eso, siempre se portan bien conmigo" (Renaud, 22 años, Mexicali, universidad incompleta, un año de experiencia laboral en Chile; comunicación personal, 20 de diciembre del 2017). 
En el mismo orden de ideas, Boulot dice: “[...] en todos mis trabajos siempre la relación es buena con todos. [...] Ya sabes, siempre hay alguien que no se lleva tan bien contigo como quisieras, [...] pero ninguno me ha hecho sentir que soy extraño" (Boulot, 36 años, Mexicali, universidad incompleta, casado, seis años de experiencia en Venezuela; comunicación personal, 21 de diciembre del 2017). De la misma forma, Kenia dice: "si todo dependiera del ambiente con los compañeros, no me movería de Tijuana" (Kenia, Tijuana, primaria completa, casada, un año de experiencia en Brasil y un año en Chile; comunicación personal, 11 de diciembre del 2017).

En definitiva, los haitianos de la oleada del 2016 a México se encuentran en un entorno laboral con empleos distintos a los que desempeñaban en Sudamérica, así como a los del mercado estadounidense al que pretendían ingresar. La mayoría llegó a México con la experiencia de Brasil, cuya política de brazos abiertos facilitó que experimentaran una inserción laboral con cierta rapidez en los segmentos formales del mercado. Como ya se señaló, su llegada a México se produjo en condiciones distintas.

Lo anterior deriva en una desilusión entre los integrantes del colectivo, la cual fue manifiesta en la mayoría de los entrevistados. La situación parece particularmente compleja en la Ciudad de México, donde existen menos empresas sometidas a regímenes laborales de excepción, como es el caso de las maquilas. En un contexto así, el mercado de trabajo se polariza notablemente entre un segmento exigente en cuanto a la posesión de documentos migratorios y de permisos de trabajo, y otro flexible, pero desprotegido y explotador. Esas disparidades hablan de las diferencias en los contextos de recepción y, posiblemente, moldearán diferencias en los ritmos de integración de los haitianos en México, incluso puede conducir a situaciones de marginación en la sociedad de asentamiento.

\section{VÍNCULOS SOCIOAFECTIVOS MIXTOS}

Con respecto a los vínculos socioafectivos, en este trabajo nos interesamos en las relaciones de pareja entre haitianos y mexicanos de las tres ciudades. Si bien existen otros tipos de relaciones de diferente naturaleza entre los dos grupos, damos prioridad a relaciones de pareja afectiva, ya que expresan un mayor grado de apertura hacia el otro. El análisis presentado aquí es una primera aproximación al tema, pero creemos que deberá profundizarse en futuros estudios.

Ahora bien, a mediados del 2017, cuando la esperanza de cruzar a Estados Unidos se alejaba, los haitianos empezaron a abandonar los albergues para rentar casas y reconstruir sus proyectos de vida. La salida de los albergues implicó la entrada de los haitianos a las colonias, compartir la cotidianidad con los mexicanos y el desarrollo de lazos de amistad, vecindad y sentimentales con miembros de las comunidades de recepción. En las tres ciudades hemos recabado testimonios sobre relaciones afectivas entre inmigrantes haitianos

y ciudadanos mexicanos, que van desde noviazgos hasta la constitución de familias a través de uniones libres o matrimoniales. Incluso, hemos encontrado mujeres embarazadas y niños 
nacidos a raíz de esas uniones. Muy a menudo, estas relaciones se desarrollan en tiempos relativamente cortos como explica Renaud, quien está en una unión libre con una mexicana:

Nos conocimos cuando estaba en el albergue. No pensé que se podía dar algo más porque no pensé que me iba a quedar en México. Cuando salí del albergue, seguíamos viéndonos más seguido. Me ayudó a mejorar mi español y yo le ayudaba con el francés. Cuando nos dimos cuenta, ya éramos novios (Renaud, 22 años, Mexicali, universidad incompleta, en unión libre con una ciudadana mexicana, un año de experiencia laboral en Chile; comunicación personal, 20 de diciembre del 2017).

Así como Renaud, Daniel conoció a su esposa cuando aún estaba hospedado en una iglesia en las afueras de Tijuana. Cuando lo entrevistamos, estaban esperando un bebé que nacería tres meses después. Daniel explica:

Todo pasó muy rápido, al principio fue una aventura. No pensaba llegar tan lejos [porque] mi objetivo era ir a Estados Unidos. Pero llegó [Donald] Trump y empecé a ver las cosas de otra forma. Cuando supimos del embarazo, decidimos casarnos [...]. Ahora el bebé llega dentro de tres meses (Daniel, 25 años, Tijuana, preparatoria incompleta, casado con una mexicana, con dos años de experiencia laboral en Brasil; comunicación personal, 16 de diciembre del 2017).

Sin embargo, no todos los casos de uniones mixtas se dan entre personas sin compromisos. Existen casos en que, ante la incertidumbre sobre la duración del tiempo de espera, migrantes comprometidos cuya pareja se encuentra en otros países, deciden entrar en "relaciones paralelas", ya sea en corresidencia o no. Entre nuestros entrevistados que estaban en esa situación, en la mayoría de los casos, la contraparte mexicana no está informada de la relación previa, pero también hay algunas que lo están. Chouloute, que está en unión libre con una ciudadana mexicana, comenta:

[...] mira, creo que la mayoría de los [hombres haitianos] terminarán uniéndose aquí. Sus novias o esposas están en Haití, Brasil, Estados Unidos. [...] Con el tiempo se van a meter con mexicanas (Chouloute, 29 años, Tijuana, con universidad incompleta, en unión libre con una ciudadana mexicana, dos años de experiencia en Brasil; comunicación personal, 27 de diciembre del 2017).

El relato de Chouloute hace eco en el de Fleurjuste, 36 años. Ese nativo de Puerto Príncipe viajó desde Brasil con su esposa y su hijo de 8 años; todos llegaron a Mexicali en octubre del 2016 y comprobaron que el cruce podía desembocar en una deportación a Haití. Fleurjuste decidió que se quedaría en México, mientras que su esposa y el menor cruzaron juntos de forma irregular a Estados Unidos en noviembre de ese mismo año. En el momento que entrevistamos a Fleurjuste, el estatus migratorio de su esposa y su hijo estaba por definirse 
en Estados Unidos. Ante la incertidumbre sobre el tiempo que tendrá que esperar antes de volver a ver a su familia, Fleurjuste se unió con una mexicana. Explicó:

Mi esposa está en el otro lado, está en Miami. No sé cuándo la voy a volver a ver. Tal vez en 10 o 15 años, o tal vez nunca, porque no sé si voy a poder cruzar. Mientras tanto, ¿qué quieres que haga? Si podía vivir solo, no me hubiera casado (Fleurjuste de 36 años, Mexicali, preparatoria completa, en unión libre con una ciudadana mexicana, tres años de experiencia laboral en Brasil; comunicación personal, 27 de diciembre del 2017).

El argumento de Fleurjuste no es aislado; Étienne, cuya esposa se encuentra en Haití, dijo:

Llevo cinco años viviendo fuera [de Haití], no sé cuándo nos vamos a reunir. Por respeto a mi familia no me junto con otra mujer. Pero tengo necesidades [...]. A mi edad, no estoy para buscar relaciones sexuales ocasionales. Simplemente tengo una novia, ni siquiera es una novia, es una amiga [...]. Es mexicana [...] tiene cuarenta y cinco años (Etienne, 54 años, Ciudad de México, primaria incompleta, casado, cuatro años de experiencia laboral en Brasil; comunicación personal, 20 de octubre del 2017).

Cabe mencionar que nuestras observaciones apuntan a que estas relaciones se dan más entre varones haitianos con mujeres mexicanas. Además de la separación conyugal, una posible explicación a esta observación es la reducida proporción de mujeres en la comunidad haitiana, como vimos con anterioridad. Además, la mayoría de las mujeres viajaron con su pareja, lo cual aumenta la dificultad de posibles relaciones afectivas nuevas dentro de la comunidad.

Sin embargo, dentro de la comunidad haitiana las relaciones mixtas no son aprobadas por todos; para algunos son "una traición", o "no tienen bases seguras". Por ejemplo, Dieuseul dice:

Para mí, los [haitianos] que se casan [con mexicanas] están locos. Imagina que me casara con una brasileña en Brasil. ¿Qué pasaría ahora? [...] Lo más seguro es que también me case con una mexicana, pero necesito tiempo para estar seguro de que me voy a quedar definitivamente en México (Dieuseul, 28 años, Ciudad de México, preparatoria incompleta, dos años de experiencia en Brasil; comunicación personal, 20 de octubre del 2017).

Por su parte, Adèle añade:

Ven a las mexicanas y de pronto las haitianas ya no tenemos valor. [...] Se enloquecen y antes de parpadear ya se casan, hasta tienen hijos. Esos matrimonios no me dan confianza (Adèle, 32 años, Tijuana, universidad incompleta, soltera, dos años de experiencia en Brasil; comunicación personal, 16 de diciembre del 2017).

En todo caso, la formación de uniones mixtas entre los haitianos y los miembros de las comunidades de recepción en México envía señales de apertura entre los dos grupos. Es decir, en ambos grupos existen personas que están dispuestas a entablar relaciones íntimas que 
suponen interacciones frecuentes y permiten mayor interpenetración cultural y comprensión mutua, no solo entre los protagonistas directos de esas relaciones, sino también a nivel comunitario. Sin embargo, los casos de "relaciones paralelas" pueden engendrar consecuencias perjudiciales para los participantes y para el resto de la comunidad haitiana.

\section{A MODO DE CONCLUSIÓN}

En este artículo analizamos la incorporación laboral y socioafectiva de los inmigrantes haitianos de la oleada del 2016 en sus tres principales ciudades de recepción en México, es decir, en Tijuana y Mexicali, Baja California, y en la Ciudad de México. En el plano laboral, se evidenció que los factores tradicionales de capital humano (escolaridad y experiencia laboral) no fueron determinantes en su inserción. Por un lado, experimentaron dificultades para transferir su capital al mercado de trabajo mexicano; por otro, los factores asociados a su calidad de inmigrantes como el estatus migratorio, el poco dominio del español o la disposición de redes limitadas en el país, restringieron sus opciones laborales. Asimismo, las especificidades de los contextos locales de recepción influyeron en sus modalidades de inserción en el mercado; en las dos ciudades del norte estudiadas, los haitianos laboran principalmente en la industria maquiladora y en pequeños negocios manejados por cuenta propia; mientras que en la Ciudad de México se insertan en los eslabones más bajos de la jerarquía laboral.

Con respecto a los lazos afectivos, se exploraron uniones mixtas entre haitianos y miembros de las ciudades de recepción. Pese al carácter reciente del colectivo haitiano y sus diferencias socioculturales con la comunidad nacional, las uniones y familias mixtas no tardaron en surgir. Más allá de las razones demográficas, las uniones entre mexicanos y haitianos reflejan cierta apertura entre los dos grupos para una interpenetración más amplia. Como señala Kalmijn (1998), esas uniones permiten acercar y vincular las redes de sus protagonistas y posibilitar que los dos grupos se conozcan y así debilitar posibles prejuicios mutuos. Sin embargo, las "relaciones paralelas" pueden generar otros prejuicios capaces de repercutir negativamente en la integración de los haitianos en México.

Los avances realizados en el mercado de trabajo y en las relaciones socioafectivas, aunque limitados e imperfectos, son indicadores de la inserción de los haitianos en ciertas esferas de sus lugares de recepción en México, y la puesta en marcha de un proceso de integración en el país. En ausencia de una estrategia pública clara en este tema, esta integración se ha apoyado ampliamente en las organizaciones de la sociedad civil, miembros de las comunidades de recepción, así como en el ingenio de los propios haitianos. México ocupa una posición singular en el mundo debido a su ubicación geográfica y a su postura ante el fenómeno migratorio a nivel global y regional, así como por sus compromisos internacionales relacionados con la migración.

No será una sorpresa que migrantes de distintas partes de la región y del resto del mundo sigan llegando a esta nación, ya sea para transitar o para radicarse permanentemente. Por 
consiguiente, es necesario que, por una parte, el país se dote de mayor capacidad para anticipar y atender las futuras oleadas de migrantes a su territorio; y por otra, es de gran importancia desarrollar políticas de integración para aquéllos que, por distintas razones, lo eligen como su hogar, especialmente para grupos y personas que no forman parte de los inmigrantes tradicionales, como es el caso de los haitianos.

\section{REFERENCIAS}

Anker, R. (1997). La segregación profesional entre hombres y mujeres. Un repaso de las teorías. Revista internacional del Trabajo, 116(3), 343-370.

Baeninger, R. y Peres, R. (2017). Migração de crise: a migração haitiana para o Brasil. Revista. Brasileira de. Estudos de População. 34(1), 119-143.

Bean, F., Leach, M., Brown, S., Bachmeier, J. y Hipp, J. (2011). The Educational Legacy of Unauthorized Migration: Comparisons across U.S.-Immigrant Groups in How Parents' Status Affects Their Offspring. International Migration Review, 45(2), 348-385.

Becker, G. S. (1964). Human Capital: A Theoretical and Empirical Analysis with Special Reference to Education. Nueva York: National Bureau of Economic Research/Columbia University.

Boumahdi, R., Lattes, J.M. y Plassard, J.-M. (2002). Marché du travail et lutte contre la discrimination : une approche pluridisciplinaire. Droit et société, (pp. 51-52), 487-508.

Bourdieu, P. (2000). Poder, derecho y clases sociales. Barcelona: Desclée.

Bowles, S. y Gintis, H. (1976). Schooling in capitalist America: Educational reform and the contradictions of economic life. Nueva York: Basic Books.

Chiswick, B. R., Lee, Y. L., y Miller, P. W. (2005). A Longitudinal Analysis of Immigrant Occupational Mobility: A Test of the Immigrant Assimilation Hypothesis. International Migration Review, 39(2), 332-353.

Clot, J. y Martínez Velasco, G. (2018). La «odisea» de los migrantes cubanos en América: modalidades, rutas y etapas migratorias. Revista Pueblos y fronteras digital, 13, 1-27.

Collins, R. (1979). The credential society. Nueva-York: Academic Press.

Consejo Nacional de Población (Conapo), Fundación BBVA Bancomer y BBVA Research. (2018). Anuario de migración y remesas. México 2018. México: Conapo/Fundación BBVA/Bancomer/BBVA Research.

Cornelius. W. A., Tsuda, T. y Valdez, Z. (2003). Human Capital versus social capital: A comparative analysis of Immigrant Wages and Labor Market Incorporation in Japan and the United States. Migraciones Internacionales, 2(1), 5-35.

Da Silva, S. A. (2013). Brazil, a new Eldorado for immigrants? The case of Haitians and the Brazilian Immigration Policy. Urbanities, 3(2), 3-18.

De la Rica, S. y Ugidos, A. (1995). ¿Son las diferencias en capital humano determinantes de las diferencias salariales entre hombres y mujeres? Investigaciones Económicas, 19(3), $395-414$ 
DeTienne, D. R. y Chandler, G. N. (2007). The Role of Gender in Opportunity Identification. Entrepreneurship Theory and Practice, 31(3), 365-386.

Duffard Evangelista, I. (2016). Del caribe haitiano a la Argentina. Trayectorias de cuerpos en movilidad humana pos-terremoto 2010. Buenos Aires: Consejo Latinoamericano de Ciencias Sociales [CLACSO].

García, B. y De Oliveira, O. (1994). Trabajo femenino y vida familiar en México, México: El Colegio de México.

Gordon, M. M. (1964). Assimilation in American Life. The Role of Race, Religion and National Origins. Nueva York: Oxford University Press.

Elliott, J. R. y Sims, M. (2001). Ghettos and barrios: The impact of neighborhood poverty and race on job matching among Blacks and Latinos. Social Problems, 48(3), 341-361.

Fernandes, D. y Gomes de Castro, M. da C. (2014). A migração haitiana para o Brasil: resultado da pesquisa no destino, en Organización Internacional para las Migraciones. La migración haitiana hacia Brasil: características, oportunidades y desafíos. (pp. 5166). Cuadernos migratorios No.6, Buenos Aires: Organización Internacional para las Migraciones.

Frijters, P., Shields, M. A., y Wheatley Price, S. (2005). Job Search Methods and their Success: A Comparison of Immigrants and Natives in the UK. The Economic Journal, 115(507), 359-376.

Kalmijn, M. (1998). Intermarriage and Homogamy: Causes, Patterns, Trends. Annual Review of Sociology, 24, 395-421.

Kalter, F. y Kogan, I. (2014). Migrant Networks and Labor Market Integration of Immigrants from the Former Soviet Union in Germany. Social Forces, 92(4), 1435-1456.

Lundahl, M. (2011). Poverty in Haiti: Essays on Underdevelopment and Post Disaster Prospects. Reino Unido: Palgrave Mcmillan.

Marrero, A. (2006). La teoría del capital social. Una crítica en perspectiva latinoamericana. Arxius de Sociología, (14), 73-89.

Massey, D. S. y Denton, N. A. (1987). Trends in the Residential Segregation of Blacks, Hispanics, and Asians: 1970-1980. American Sociological Review, 52(6), 802-825.

Méroné, S. C. (2019). ¿Es una ventaja tener un progenitor estadounidense? Influencia de la ascendencia nativa en el logro educativo y la inserción laboral de los mexicanos de segunda generación en Estados Unidos. En Consejo Nacional de Población, Situación Demográfica de México 2019, (pp. 161-174). México: Consejo Nacional de Población.

Méroné, S. C. y Castillo, M. Á. (2018). La reciente ola de haitianos a México: ¿transito prolongado o formación de un nuevo destino? Martínez de la Peña, M., Martínez Caballero, G., Ramos Martínez, L. F. (Coord.) Prontuario sobre poblaciones migrantes en condiciones de vulnerabilidad, (pp. 56-59). México: Unidad de Política MigratoriaSecretaría de Gobernación.

Milani, C. R. S., Lazo Vergara, M. C., Alba Vega, C., y Charles, A. (2016). À cinq années du tremblement de terre en Haïti. Leçons apprises de la Coopération Sud-Sud : le cas 
du Brésil, du Chili et du Mexique. México: Comisión Económica para América Latina y el Caribe.

Montoya-Ortiz, M. S. y Sandoval-Forero, E. A. (2018). Migrantes haitianos en México: un nuevo escenario migratorio. Huellas de la migración, 3(6), 133-156.

Muñoz, O. H. (2009). Factores determinantes de la participación laboral: aspectos conceptuales. Tendencias, 10(1), 87-116.

París Pombo, M. D. (Coord.) (2018). Migrantes haitianos y centroamericanos en Tijuana, Baja California, 2016-2017. Políticas gubernamentales y de la Sociedad Civil. México: Comisión Nacional de Derechos Humanos/El Colegio de la Frontera Norte.

Peláez, E., González, L., Pinto da Cunha, y J. M. (2008). Dimensiones de la segregación residencial en el Gran Córdoba (Argentina) y comparación con la Región metropolitana de Campinas (Brasil). Carta Económica Regional, (100), 31-47.

Portes, A. (1998). Social Capital: Its Origins and Applications in Modern Sociology. American Review of Sociology, 24, 1-24.

Portes, A. y Rumbaut, R. G. (2001). Legacies: The Story of the Immigrant Second Generation. Berkeley: University of California Press.

Qian, Z. y Lichter, D. T. (2007). Social Boundaries and Marital Assimilation: Interpreting Trends in Racial and Ethnic Intermarriage. American Sociological Review, 72(1), 68-94.

Secretaría de Gobernación (Segob). (2017). Boletines Estadísticos [base de datos]. Unidad de Política Migratoria, Registro e Identidad de Personas. Recuperado de http://www.politicamigratoria.gob.mx/es/PoliticaMigratoria/CuadrosBOLETIN?Anual $=2017 \&$ Secc $=3$

Vaillant, M., Fernández, A. y Kaztman, R. (2001). Desarrollo humano en Uruguay. Inserción internacional, empleo y desarrollo humano. Montevideo: Comisión Económica para América Latina y el Caribe/Programa de las Naciones Unidas para el Desarrollo.

Vega Cánovas, G. y Alba Vega, C. (2012). La política de cooperación de México con Haití. En G. Vega Cánovas y C. Alba Vega. (Coord.), Haití y México: hacia una nueva política de cooperación, (pp. 35-61). México: El Colegio de México.

Telles, E. y Esteve, A. (2019). Racial Intermarriage in the Americas. Sociological Science, 6, 293-320.

Yee Quintero, J. C. (2017). Caracterizando a solicitantes de asilo a Estados Unidos: el caso de los haitianos en 2016. En R. Pérez Rojas (Coord.), Vidas en vilo. Historias y testimonios de migrantes internacionales, (pp. 53-83). Tijuana: ILCSA Ediciones. 